and peripheral blood markers of disease stage. Among the latter, identification of PSA mRNA by reverse transcriptase polymerase chain reaction is promising $^{20}$ but controversial. ${ }^{21}$

MARK R FENELEY

Department of Urology, St Bartholomew's Hospital, West Smithfield, London EC2A $7 B E$, United Kingdom

M CONSTANCE PARKINSON

UCL Hospitals Trust/Institute of Urology and Nephrology, Rockefeller Building, University Street, London WC1E 6FY, United Kingdom

1 Catalona WJ, Richie JP, Ahmann FR, Hudson MA, Scardino PT, Flanigan $\mathrm{RC}$, et al. Comparison of digital rectal examination and serum prostate specific antigen in the early detection of prostate carcinoma: results of a multicenter clinical trial of 6,630 men. F Urol 1994;151:1283-90.

2 Brewster SF, Kemple T, Maclver AG, Astley JP, Gingell JC. The Bristol prostate cancer pilot screening study-a 3 year follow up. $\mathrm{Br} \mathcal{f}$ Urol 1994;74:556-8.

3 Rosen MA. Impact of prostate-specific antigen screening on the natural history of prostate cancer. Urology 1995;46:757-68

4 McNeal JE, Bostwick DG, Kindrachuk RA, Redwine EA, Freiha FS Stamey TA. Patterns of progression in prostate cancer. Lancet 1986;i:60-3. 5 Stricker HJ, Ruddock LJ, Wan J, Belville WD. Detection of non-palpable prostate cancer. A mathematical and laboratory model. Br f Urol 1993;71: 43-6.

6 Häggman M, Nybacka O, Nordin B, Busch C. Standardization of in vitro mapping with multiple core biopsies of total prostatectomy specimens: localization and prediction of tumour volume and grade. $\mathrm{Br} \mathcal{f}$ Urol 1994;74:617-25.

7 Humphrey PA, Keetch DW, Smith DS, Shepherd DL, Catalona WJ. Prospective characterization of pathological features of prostatic carcinomas detected via serum prostate specific antigen based screening. $\mathcal{F}$ Urol 1996;155:816-20.
8 Lerner SE, Seay TM, Blute ML, Bergstralph EJ, Barrett D, Zincke H. Prostate specific antigen detected prostate cancer (clinical stage T1c): an interim analysis. F Urol 1996;155:821-6.

9 Epstein JI, Walsh PC, Carmichael M, Brendler CB. Pathologic and clinical findings to predict tumour extent of non-palpable (stage T1c) prostate cancer. $\mathcal{F} A M A$ 1994;271:368-74.

10 Bostwick DG. Prospective origins of prostate carcinoma. Cancer 1996;78: 330-55.

11 Jones EC, Young RH. The differential diagnosis of prostatic carcinoma. Am f Clin Pathol 1994;101:48-68.

12 Epstein JI. The diagnosis and reporting of adenocarcinoma of the prostate in core needle biopsy specimens. Cancer 1996;78:350-5.

13 Simpson JG, Lessells AM, Burnett RA, Howatson SR, Lang S, Lee FD, et al. Observer variability in the histopathological assessment of prostatic needle biopsies [abstract]. Pathology International 1996;46(suppl 1):A810.

14 Bostwick DG, Qian J, Bergstralph E, Dundore P, Dugan J, Myers RP, Oesterling JE. Prediction of capsular perforation and seminal vesicle invasion in prostate cancer. $\mathcal{F}$ Urol 1996;155:1361-7.

15 Peller PA, Young DC, Marmaduke DP, Marsh WL, Badalament RA Sextant prostate biopsies. Cancer 1995;75:530-38.

16 Terris MK, Haney DJ, Johnstone IM, McNeal JE, Stamey TA. Prediction of prostate cancer volume using prostate specific antigen levels, transrectal prostate cancer volume using prostate specific antigen levels, tran

17 Cupp MR, Bostwick DG, Myers RP, Oesterling JE. The volume of prostate cancer in the biopsy specimen cannot reliably predict the quantity of cancer in the radical prostatectomy specimen on an individual basis. $\mathcal{F}$ Uro 1995;153:1543-8.

18 Bostwick DG. Gleason grading of prostatic needle biopsies. Am 7 Surg Pathol 1994;18:796-803.

19 von Eschenbach AC, Brawer MK, di Sant 'Agnese PA, Humphrey PA Mahran H, Murphy GP, et al. Exploration of new pathologic factors in Mahran H, Murphy GP, et al. Exploration of new pathologic factors in terms of potential for

20 Katz AE, De Vries GM, Olsson CA, Benson MC, Swanton P, Ikeguchi EF, Buttyan R. Molecular staging of genitourinary malignancies. Urology 1996 47:948-58.

21 Smith MR, Biggar S, Hussain M. Prostate-specific antigen messenger RNA is expressed in non-prostatic cells: implications for detection of micrometastases. Cancer Res 1995;55:2640-4.

\title{
Colorectal cancer reporting: are we failing the patient?
}

In the United Kingdom, about 25000 cases of colorectal cancer occur each year and more than $80 \%$ of these will be treated by surgical resection. Thus the average laboratory can expect to receive at least 100 resections annually. Despite being a routine part of pathological practice, results from the Welsh audit undeniably demonstrate a disturbing poverty of pathological reporting of such resection specimens. ${ }^{1}$ We believe that these results reflect a countrywide weakness of colorectal cancer pathological reporting. There have been audits performed in many regions of England and in Scotland, and these have shown broadly similar results. Disappointingly the quality of reporting seems to have improved little since the poor performance was highlighted more than 15 years ago. ${ }^{2}$ What is most disturbing about the Welsh audit is the fact that so few hospitals and reports even fulfil the minimum dataset. This is of critical importance for individual patient prognosis, for the determination of postoperative adjuvant chemotherapy and radiotherapy, to provide an indicator of the quality of rectal surgery, and for the overall management of the disease.

Colorectal cancer pathological reporting has received much publicity in the past 15 years. Why, then, is the reporting not even fulfilling these minimum standards? We believe that much of the responsibility for these deficiencies can be laid at the heart of the pathological establishment, in education of pathologists, and the attitude of senior staff towards the macroscopic assessment of specimens. There is no doubt that if the "cut-up" of a colorectal cancer specimen is poor then no amount of sophisticated microscopic assessment can redeem the position. Lymph node harvesting, evaluation of local spread, and the determination of margin and serosal involvement all demand diligent assessment and dissection of the specimen and rely little on microscopic evaluation. However, macroscopic assessment is still poorly taught and certainly does not figure highly in Royal College examinations. Prioritisation in pathological practice remains with microscopic assessment and in many centres the cut-up is still largely the province of junior pathologists. We can understand that pathologists are not inclined towards the dissection of a poorly prepared colorectal cancer specimen but current practice demands that such specimens are adequately prepared so that the maximum amount of information can be derived. While the attitude of most pathologists towards the Ashworth dilemma ${ }^{3}$ was wholesale condemnation, the proposal that well trained MLSOs should dissect specimens may require further consideration if pathologists do not have the time or motivation to assess such specimens adequately.

The importance of the pathological reporting of colorectal cancers has increased enormously for two main reasons: first, the recognition of the significance of involvement of circumferential (radial, mesorectal) margins in rectal cancer with the potential for the pathologist to audit the technical quality of the surgery; and second, the influence of pathological results on the decision to institute adjuvant therapy. The results of assessment of circumferential margin involvement were particularly poor in the Welsh audit. Yet this is the major determinant of local recurrence in rectal cancer, a feature with a profound influence on morbidity and mortality. ${ }^{4-6}$ Failure to identify circumferential margin involvement in rectal cancer denies the patient the chance to be considered for postoperative radiotherapy which might help to salvage the situation. It has been shown how few useful data can be gained from the assessment of proximal and distal margins of excision ${ }^{7}$ : pathologists should instead concentrate on the assessment of circumferential margins and the serosal surface that 
provide much more useful prognostic and management information. As an important clinical audit, good pathological assessment can identify surgeons with a high circumferential margin involvement rate so that they can improve the quality of their surgery, usually by ensuring the complete removal of mesorectal tissue without violation of the mesorectal fascia. ${ }^{8}$

One of the problems confronting practising pathologists is the contradictions in the literature over what factors and what staging systems are the most useful for prognostication and further patient management. The literature would appear to demonstrate that no less than 22 pathological parameters have independent prognostic significance, varying from those of undoubted major importance, such as lymph node involvement and circumferential margin involvement in rectal cancer, to those which are highly dubious and not to be recommended for routine use. ${ }^{9}$ Furthermore, there is little international agreement on the most useful staging system. Most pathologists continue to use solely the Dukes' system ${ }^{11}$; however, the TNM system is rapidly gaining in popularity in the United Kingdom, particularly among surgeons and oncologists.

In the Welsh audit, only pathological reports were assessed and there may well be further deficiencies in the assessment and interpretation of macroscopic specimens and histological sections. For instance, there is evidence to indicate that the quantity of lymph node harvest has a direct effect on staging. ${ }^{12}{ }^{13}$ In the South Western Region Colorectal Cancer Audit, the data suggested that $25.7 \%$ of cases would have been upstaged from Dukes' A/B to Dukes' C with exemplary lymph node harvesting (mean 19.6) compared with other centres with a mean of 5.88 (Pheby DFH, Levine DF, Shepherd NA, unpublished data). In Germany, the number of lymph nodes found directly influenced the frequency of Dukes' $C$ cases $(21.5 \%$ for $1-5$ nodes, $38.3 \%$ for $6-11$ nodes, $45.6 \%$ for $12-20$ nodes, and $48.3 \%$ for $>20$ nodes).${ }^{13}$ As Dukes' staging is the most powerful determinant of postoperative adjuvant therapy, the importance of adequate lymph node assessment is all too evident.

It is clear that a small number of unequivocally useful pathological parameters only should be advocated for routine reporting, ${ }^{14}$ and that other data should only be recommended for research type protocols such as that developed by the United Kingdom Coordinating Committee for Cancer Research (UKCCCR). There must, however, be a dependable mechanism for the widespread promulgation of new data. For instance, one of us has recently shown that, in an unselected, prospective study of colonic cancer, peritoneal involvement was the single most powerful prognostic determinant, and predicted cases which subsequently recurred within the peritoneal cavity. ${ }^{15}$

What of the future? We concur entirely with our Welsh colleagues that the future lies in structured template proformas. We accept that such proformas are not popular among pathologists and we agree that they should not, and must not, replace free text reports. Instead they should be seen as an aide memoire to ensure that all useful data are recorded. A colorectal cancer audit performed in Yorkshire has demonstrated that the use of standardised protocols is the best way to ensure that adequate data are provided and this method has been adopted by busy district general hospital pathologists in Yorkshire (Wyatt JI 1996, personal communication). There has been a veritable explosion of colorectal cancer reporting protocols, both national (Royal College of Surgeons/Association of Coloproctology, UKCCCR) and regional, all of which are subtly different. There have also been many national (notably through the RCS/ACP Guidelines for the Management of Colorectal Cancer) and regional initiatives through audits to improve pathological reporting.

What is required now is national leadership to coordinate the development, and more importantly the general acceptance, of a national protocol for the reporting of colorectal cancer. It is with much anticipation that we report the formation of a Royal College of Pathologists Working Group, by the President, Professor RNM MacSween, under the chairmanship of Professor JP Sloane, to advise on the reporting of common cancers and to formulate national guidelines and to provide the mechanism for the updating of such guidelines as new data becomes available. We strongly advocate the endorsement of the RCS/ACP proforma for colorectal cancer reporting and we fervently hope that the Royal College of Pathologists will ratify its use for routine reporting. Only by such a coordinated plan of action by a national pathology organisation can we hope to achieve acceptable reporting standards that are evidently so lacking. Pathologists need these for their own credibility; patients require them to enhance their chances of cure from an all too frequently fatal condition.

N A SHEPHERD

Gloucester Gastroenterology Group,

Gloucestershire Royal Hospital,

Great Western Road, Gloucester GL1 3NN, United Kingdom

P QUIRKE

Department of Histopathology and Centre for Digestive Diseases Research, School of Medicine, Algernon Firth Building,

University of Leeds, Leeds LS2 9fT, United Kingdom

1 Bull AD, Biffin AHB, Mella J, Radcliffe AG, Stamatakis JD, Steele RJC, et al. Colorectal cancer pathology reporting: a regional audit. $¥$ Clin Pathol 1997;50:138-42.

2 Blenkinsopp WK, Stewart-Bown S, Blesovsky L, Kearney G, Fielding LP. Histopathology reporting in large bowel cancer. $\mathcal{F}$ Clin Pathol 1981;34:50913.

Ashworth TG. Personal view-The future for histopathology: protectionism or prudence? $B M F$ 1994;309:417.

4 Quirke P, Dixon MF, Durdey P, Williams NS. Local recurrence of rectal adenocarcinoma due to inadequate surgical resection. Histopathological study of lateral tumour spread and surgical excision. Lancet 1986;ii:996-9.

5 Abulafi AM, Williams NS. Local recurrence of colorectal cancer: the problem, mechanisms, management and adjuvant therapy. $\mathrm{Br} f$ Surg 1994;81:7-19.

6 Adam IJ, Mohamdee MO, Martin IG, Scott N, Finan PJ, Johnston D, et al. Role of circumferential margin involvement in the local recurrence of rectal Role of circumferential margin in

7 Cross SS, Bull AD, Smith JHF. Is there any justification for the routine examination of bowel resection margins in colorectal adenocarcinoma? $\mathcal{f}$ Clin Pathol 1989;42:1040-2.

8 Quirke P. Limitations of existing systems for staging for rectal cancer: the forgotten margin. In: Soreide O, ed. Rectal cancer research. Berlin: SpringerVerlag, 1997:63-81.

9 Shepherd NA. Pathological prognostic factors in colorectal cancer. In: Kirkham N, Lemoine NR, eds. Progress in pathology. 2nd ed. Edinburgh Churchill Livingstone, 1995:115-41.

10 Hermanek P, Sobin LH. Colorectal carcinoma. Prognostic factors in cancer Berlin: Springer-Verlag, 1995:64-79.

11 Fenoglio-Preiser CM, Pascal RR. Other tumours of the large intestine. In: Whitehead R. Gastrointestinal and oesophageal pathology. Edinburgh: Churchill Livingstone, 1989:747-68.

12 Scott KWM, Grace RH. Detection of lymph node metastases in colorectal carcinoma before and after fat clearance. Br $\mathcal{F}$ Surg 1989;76:1 165-7.

13 Hermanek P, Henson DE, Hutter RVP, Sobin LH. Appendix II. Colorectal carcinoma. UICC TNM Supplement-A commentary on uniform use. Berlin Springer-Verlag, 1993:69-71.

14 Jass JR. Prognostic factors in rectal cancer. Eur $\mathcal{f}$ Cancer 1995;31:862-3.

15 Shepherd NA, Baxter KJ, Love SB. The prognostic importance of peritoneal involvement in colonic cancer: a prospective evaluation. Gastroenterology. [In press.] 